\title{
Projective Interpretation of Intelligence Tests
}

Y. A. LEJEUNE, Ph.D.

Psychologist, Johannesburg Child Guidance Clinic.

Intelligence test results given in the form of I.Q. Only are often very misleading, particularly where the subject is a deviate one, ticulas is the case with most children scen at child guidance or speech clinics. In all cases a Jualitative report is necessary, dealing with ituritubiect's attitudes to the test situation and io the examiner, in order to determine whether the I.Q. is a valid one or not; and in addition a good test report must include some assessment of the subject's personality. This is particularly important where it is not possible to give a battery of personality tests as an aid to diagnosis, and for this reason projective interpretation of intelligence test responses is useful, because it can throw light on aspects of personality which may not be revealed in other diagnostic interviews.

A standard intelligence test differs from a true projective test mainly in the degree of structuring of the stimuli presented to the subject. The questions are framed in such a way that there is-or should be-very little ambiguity, and in theory the questions should have exactly the same mecming for all subjects. In practice, however, there is a wide variation in the amount of ambiguity present in the test stimuli, and in many sub-test items there is ample opportunity for the subject to interpret the meaning of the stimulus in terms of his own personality drives. As a general rule. it:e more neurotic the subject, the more likely he is to produce these projective responses.

Some examples of responses to the S.A. Individual Scale of Intelligence may illustrate this point. Even a fairly structured test, "Are you a little 'girl or a lit!le boy?" may produce a response which is emotionally determined. A iesponse of "No, I'm big" is often related to feeling of insecurity, and frequently a girl may insist that she is a boy, even though she knows cuite well that she is not. Less often $a$ boy says that he is a girl, because of a fear of his own masculinity.

There is conother group of items in the Individual Scale, where the questions ore less structured, but which produce deviate responses in the less adjusted cases. I vould include in this category the comprehension tests, which usually produce a standard suczess or failure, but which may also reveal attitudes of dependence or withdrawal. A very defendent child may preface his replies with
"Ask my mommy." and in one case of an overprotected child with hypochondriacal symptoms, the answer to "What should you do before beginning something dificult?" was "Rest."

Timid, over-anxious children, or those with strong guilt feelings, tend to produce response which stress the dangers of the outside world. and they vill do this even when the test questions are moderately structured, e.g., "A sncise, a cow and a bird are alike because they can all hurt you;" or, in the sentence-moking test. "A boy swam in the river and cut himself on a stone and was drowned." instead of the more usual " $A$ boy threw a stone in the river." Disiortions resuliting from timidity may also appear in the memories of the reading passage, if the subject "recalls" death or injury. Sibling rivalry or interest in the birth of a new saby may also be shown in these tests, e.g., in one case of this type the subject's rescorses to the differences test were in terms of origin-"A stone comes from the ground, and an egg from a hen, milk comes from a cow and water from a tap" ; and this was followed by what oppeared to be a birth-interest response on the similarities tes:- "A dog and a horse are the same because they've both got big tummies."

In addition to these test items, there are three sub-items on the Individual Scale where the stimuli are so little structured thot they mignt almost be thought of as projective items. The first of these is the picture interpretation test occurring at year 13 . The pictures themselves are not as ambiguous as those of a Themotic Apperception test, and the emotions devicted are fairly clear; but the cause of the emotions is not clear, and for this reason the interpretations given may be very revealing about the subiect's mxieties or wishes. References to food deprivation, or quarre!ling between the parents-" The father's left them, and they have nobody to look after them"do not necessarily reflect the real home situation, but these resconses do indicate the ncture of the child's phantasies and sources of onxiety.

Another test of this type is the word association test. For the most part the normal child will give words which are inspired by what he sees around him-"pencil, pen, block. etc."-but the more disturbed subject is likely to produce responses which are associoted 
with phantasy. One girl sex-deliquent produced 35 boys' names within one ininute, an achievement which most people would find impossible to emulate. Other subjects of the same type may produce words associated with exhibitionistic behoviour-e.g., referring to dress, parties, ornaments, etc. Another frequent type is the response met with among regressed or immoture subjects, the rood resconse, where a large number of the vords are related to food or eating; and among the more agoressive children the words may refer to fighting-weapons, battles, etc.

The third test of this type is perhaps the most revealing of ail, and has been selected for special study. This is the Ball-and-field test, which from our point of view has two advantages over all the other sub-tests in the scale. In the first place it appears at two levels on the S.A. Individual Scale - at year 9 and year 12, so that nearly all primary school children, and a large number of high school children are likely to do the test. And in the second picze, it is the least structured of al the test iterns, and therefore produces more emotionally conditioned responses than any of the other items.

\section{SUBJECTS AND PROCEDURE IN THE PRESENT STUDY :}

The subjects for this study were 200 children seen at the Johannesburg Child Guidance Clinic, selected on the basis of the most recent cases who had done the Ball-and-field test as part of the routine Individual Scale examination. The age range was 5 years 7 months to 15 years, with a median age of 9 years 4 months: Mental age range was 6 years 3 months to 15 years 8 months, median 9 years 2 months, and the I.Q. ronge was 64 to 148 , median 96. In all cases the Ba!l-and-field test was given as part of the S.A. Individual Scale. with the standard instructions, but in addition the reaction time and total time taken for the test were recorded, as it was felt that deviations from the norm in time scores might indicate the presence of anxiety. Any comments on the test by the subject, or questions about it were also noted.

The records of the group were then divided into passes or failures, using the 9-year level scoring as a basis for a pass, and then these two groups were further sub-divided on the basis of similarity of patterns. The psychiatric diagnosis for each case was then compared with others in the same sub-group, in order to determined whether the Bail-and-field patterns could be correlated with patterns of personality organisation.

\section{A. PASSES :}

RESULTS.

Group 1-Normal passes, with normal reaction time (below 7"). (See diagrams 1-3). This group consisted of ôl cases, of whom 44 were diagnosed as "well adjusted."

Group 2-Normal passes (similar to group 1) but with excessively long reaction timesover 7". There were 13 cases in this group, all of whom were diagnosed as responding to "excessive frustration"; i.e., although not well-adjusted, these children were not typical cases of maladjusted personalities.

Group 3-Vertical lines (diagram 4). The 5 cases in this group were all diagnosed as "having marked feelings of deprivation, demanoing indulgence, or narcissistic."

Diagram 5, a combination of "normal" horizonal lines and vertical ones (diagram 5) was produced by a child referred to the clinic for stealing, and was diagnosed as "feeling deprived, because of the mother's self-indulgence"; but the stealing stopped ofter one interview with the child, and two with the mother, so that it was coparent that the maladjusiment was not very deep-rooted.

Group 4-Excessively careful filling of the Field (dicgram 6). All 5 cases in this grouo were diagnosed as cossessional, and 4 of them were enuretic. Three were having difficulty at school because of "slow vork."

Group 5-Success tollowed by flight from the field (diagram 7). The 3 cases in this group were described as "Over-conscientious," but 2 of them shoved conversion symptoms, and one was referred for school difficulty.

Group 6-The "Phallic" response (diagram 8). The naming of this pattern was a psychologist's hunch, but was borne out by the problems shown by the 7 cases in this group. Five of them were referred for sex difficul. ties, and the other 2 were enuretics, whose enuresis was related to over-stimulation of sex interests.

Group 7-Confused passes (diagram 9). Of the 19 cases in this group, 16 were described in the psychiatric report as "tirnid" or "apprehensive", 14 of them were referred for school difficulty, although only 4 of them have I.Q.'s below 90. They are apparently children whose anxiety leads to confusion in thinking. 

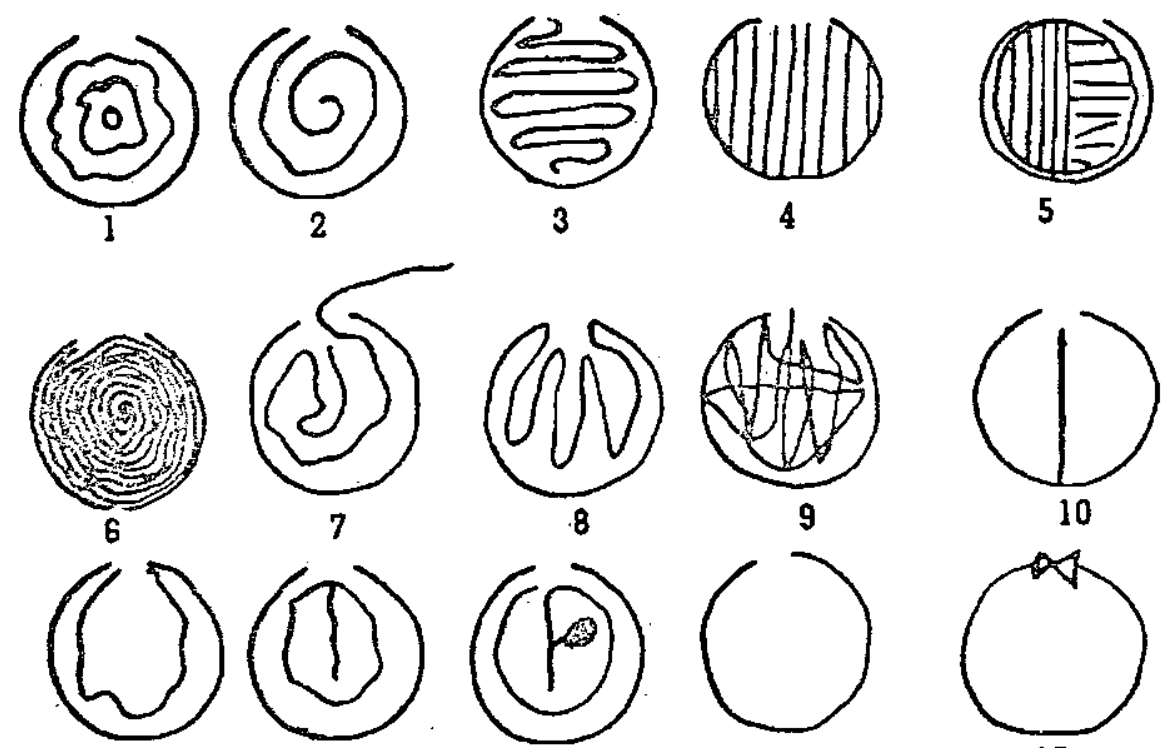

7

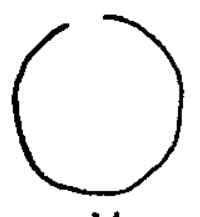

14

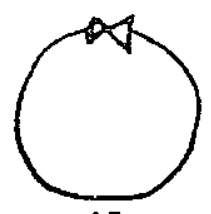

15

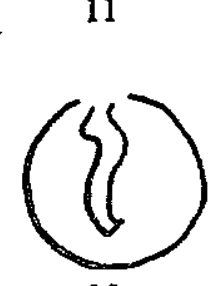

16

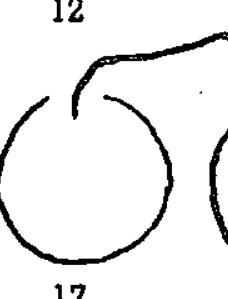

17
13
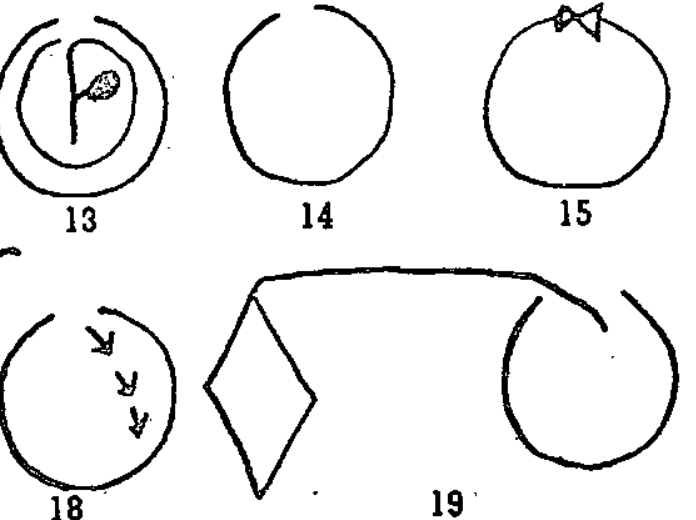

19

Group 8-Normal pattern, long reaction time, accomparied by much questioning of the examiner. These two cases were both referred for/school difficulties, and were diagnosed as being dependent and submissive.

\section{B. FAIURES :}

In assessing the importance of these patterns, the questions should be asked: "What couses failure on this test? In some cases it may be sheer intellectual inadequacy, but in the cases studied, $62 \%$ of the children had inental ages over 9 years, and should have passed the test at the 9-year level, while a further $14 \%$ had mental ages over 8 years 6 months, and might possibly hove passed it, as they passed other tests at the 9-year level. In this group, therefore, it is possible that failure was due to emotional factors, related to the general neurotic pattern of failure on nonverbal tests, or to anxiety as a result of the lack of structuring in the stimulus. The type of failure throws more light on this emotional sactor.

In none ot the forlure groups are there more than $10 \%$ of the cases and it is therefore not possible to talk about a "normal failure."
Group 9-Single straight line (diagram 10). of the 20 cases in this group, 11 were described as being "negative" or "resentful to the mother," and 9 were diagnosed as "the mother, and 9 were diagnosed as would appear that this is the pattern of least effort and that this may arise either from unwillingness to follow the test instructions, or from dependence and helplessness.

Group 10-A circle with or without a line to the centre (diagram 11 and I2). 13 of the 16 cases in this group were described as timid, insecure or withdrown, and 15 of them had I.Q.'s below 90. This oppears to be the pattern of the timid, inadequate personality, with a low I.Q.

Group 11-Drawing the ball (diagram 13). of the 9 cases in this group, 5 were referred for stealing, and the other 4, referred for aggressive behaviour, cane from materially deorived homes. All 9 have I.Q., i.e, all these cases have on interest in material possessions, and all have difficulty in dealing with problems requiring abstract thinking becoruse of the low level of intelligence.

Group 12-Following the outline (diagram 14) These 8 cases were all referred for school 
12

T 85 .

difficulty, and 7 of them had 1.Q.'s below 85 . The other child, with all child in a bright sidered to be the dull apparently reflects family, and this pattern apparenty inadethe children s awareness ol theed for outside quacy, wit

support.

Group 13- "Closing the gate" (diagram 15) in this group were all described The 5 cases in this grouphown " and in 4 as "dependent, timid, withdrawn' as being cases the parents were described as bildren's restrictive and intolerant of the a group of dernonds. This appeciss to be a group of demcrition who must "close the gate" timid children, who must "cher their own pro on the tection.

Group 14-Drawing a path (diagram 16) This group of 5 children were also timid, but differs from the previous group in that their parents are described as over prom to tive, so that it is not necess

exclude the outside world. field (diagram 17).

Group 15-Going out of the field (diagram also timid, but The 4 cases in this group are also timcourage these children have parents who encourage their fears and flight react

the parents own timidity.

Group 16-Marking the parth with arows (didgram. 18). The 3 cases in this group we all all referred for school difficulties, and all had I.Q.'s below 80 . They appecr to be children aware of their own inadecus with who attempt to cover up the problem.

a grandiose solution to the problem.

Group 17-Joining the "field" and the diamond (diagram 19). The relation between diamond and field on the record sheot fel test is quite fortuitous, but three cases flight obliged to join the two. This il cases the direction reaction, because in all cases the directionof the line is towards the fleld. The of the bolism may be understood in terms of the family background of these children. come from home where there was consider able disagreement between the partics, and all cases related to sexual dillum crildren in the psychiatric interview, these child

showed anxiety about the auarelling. 11 cases

Group 18-Miscellaneous patierns. II cases could only be classified as "unclassifiable. All this group has in common is that these patterns are unlike all others. "narcissistic." children, 6 were diagnosed as "narcissistic" and 2 as "anti-socicl, and it is possible that the exceptional pattern results lrom cown way sistence on doing things in on
CONCLUSION :

Because of the small number in each group Because of the stion may be necessary in this theretation: but it is clear leid of projective interpretation , butween personality hat relationships do exist between personatity patierns and response patterns such as those in the Ball-and-field test. The ussistance in of interpretation may be of assistan for exproblems of differential diagnosis, as lor due ample in distinguishing betwism or timidity, or to lov intelligence, negativism or limalitiust. assessing degree of adjustment or inaladist nent.

Sponsor:

\section{Sir Ernest Oppenheimer}

To whom we express our sincere thanks

The finest selection

of Speech and Music appreciation records for children are always available

on all speeds

at

"The Connoissetrs. Record Shop"

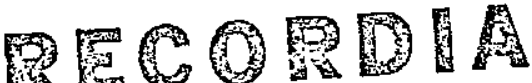

Funoto \& Gremophasa co.

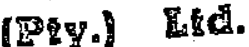

103a Eloff Street Phone: 22-1625

P.O. Box 2400

$22-5445$ 